Supporting Information for:

\title{
Unveiling an NMR-Invisible Fraction of Polymers in Solution by Saturation Transfer Difference
}

\author{
Ramon Novoa-Carballal, ${ }^{a}$ Manuel Martin-Pastor, ${ }^{b}$ and Eduardo Fernandez-Megia*a \\ ${ }^{a}$ Centro Singular de Investigación en Química Biolóxica e Materiais Moleculares (CIQUS), \\ Departamento de Química Orgánica, Universidade de Santiago de Compostela, Jenaro de la Fuente s/n, \\ 15782 Santiago de Compostela, Spain. \\ ${ }^{b}$ Unidade de Resonancia Magnética, Área de Infraestructuras de Investigación, CACTUS, Universidade \\ of Santiago de Compostela, 15782 Santiago de Compostela, Spain.
}




\section{Table of Contents}

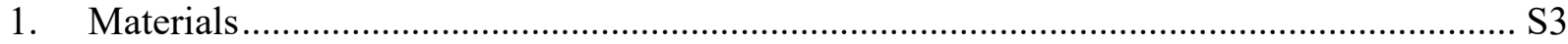

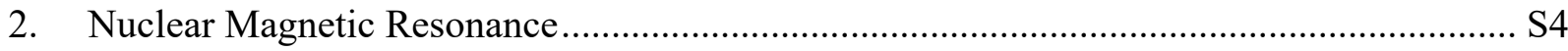

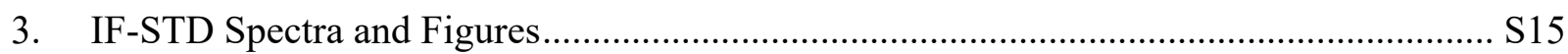

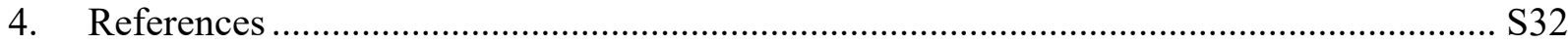




\section{Materials}

Chitosan $\cdot \mathrm{HCl}(\mathrm{CS})$ was obtained from FMC BioPolymer as hydrochloride salt [Protasan $\mathrm{Cl} 113$, batch number FP-110-02; $M_{\mathrm{w}} 80 \mathrm{kDa}$, PDI 1.48 by SEC-MALLS; degree of acetylation (DA) $14 \%$ by ${ }^{1} \mathrm{H}$ NMR]. ${ }^{1}$ Carrageenan ( $M_{\mathrm{n}} 647 \mathrm{kDa}$, PDI 1.61, by SEC-MALLS) was obtained from CEAMSA and ulvan ( $M_{\mathrm{n}} 524 \mathrm{kDa}$ by SEC-MALLS) extracted from green algae. Poly(propylene imine) dendrimer of G4 (PPI-G4) with batch number 32Am-12cc-C01 was obtained from SyMOChem. Pullulan samples were purchased from Polymer Standards Service ( $M_{\mathrm{n}} 11.8 \mathrm{kDa}$, PDI 1.10; $M_{\mathrm{n}} 112 \mathrm{kDa}$, PDI 1.12; $M_{\mathrm{n}} 788 \mathrm{kDa}$, PDI 1.23). Poly(vinyl alcohol) (PVA) was purchased from Alfa Aesar ( $M_{\mathrm{w}} 306 \mathrm{kDa}$, PDI 1.13 by SEC-MALLS, batch number B08R009). All other polymers were obtained from Sigma-Aldrich-Fluka: poly-L-lysine $\cdot \mathrm{HBr}\left(\mathrm{PLL}, M_{\mathrm{n}} 45 \mathrm{kDa}\right.$, from Sigma, batch number 120M5014V), polyvinylpyrrolidone (PVP, average molecular weight $360 \mathrm{kDa}$, from Aldrich, batch number 1300807), poly(acrylic acid) (PAA, $M_{\mathrm{v}} \sim 450 \mathrm{kDa}$, from Aldrich, batch number U12990), hyaluronic acid ( $M_{\mathrm{w}} 160 \mathrm{kDa}$ by SEC-MALLS, from Aldrich, batch number 057k3789), poly-L-glutamic acid sodium salt (PGA, $M_{\mathrm{v}} 14 \mathrm{kDa}$ and $35 \mathrm{kDa}$, from Fluka, batch numbers 1255079 and $017 \mathrm{k} 5108 \mathrm{v}$, respectively), branched polyethyleneimine (PEI-branched, $M_{\mathrm{w}}$ $\sim 25 \mathrm{kDa}$ by LS, from Aldrich, batch number 02816BD), poly(ethylene glycol) (PEG, $M_{\mathrm{n}} 10 \mathrm{kDa}$, from Aldrich, batch number 11180231041899$)$, polyacrylamide $\left(M_{\mathrm{v}} 5000 \mathrm{kDa}\right.$, from Aldrich, batch number 1285399), poly(styrenesulfonate) (PSS, $M_{\mathrm{v}} 1000 \mathrm{kDa}$, from Aldrich, batch number 10805KC), and sodium poly(methacrylate) (PMAA, $M_{\mathrm{v}} 30 \mathrm{kDa}$, PDI $<1.2$, from Aldrich, batch number 1405491).

Depolymerization of CS. Commercial CS (Protasan C1 113) was depolymerized by addition of nitrous acid. ${ }^{2}$ By adjusting the amount of $\mathrm{NaNO}_{2}$ added and fractionating by precipitation with 
EtOH or ultrafiltration (Amicon YM1), CS samples of lower MW were obtained: $M_{\mathrm{n}} 2.3 \mathrm{kDa}$, PDI $1.15 ; M_{\mathrm{n}} 5.9 \mathrm{kDa}$, PDI $1.15 ; M_{\mathrm{n}} 29 \mathrm{kDa}$, PDI 1.19 by SEC-MALLS.

\section{Nuclear Magnetic Resonance}

CS was dissolved in a pD 4.5 buffer solution consisting of $350 \mathrm{mM} \mathrm{CD}_{3} \mathrm{CO}_{2} \mathrm{D} / 135 \mathrm{mM} \mathrm{NaOD}$ in $\mathrm{D}_{2} \mathrm{O}$. All other polymer solutions were prepared in $\mathrm{D}_{2} \mathrm{O}$, unless noted. NMR spectra were acquired on an Agilent Inova or Bruker NEO spectrometers operating at $17.6 \mathrm{~T}(750 \mathrm{MHz}$ resonance of proton), Bruker DRX-500 (operating at $11.74 \mathrm{~T}, 500 \mathrm{MHz}$ resonance of proton), Varian Inova 400 (operating at 9.39 T, $400 \mathrm{MHz}$ resonance of proton) or Bruker DPX-250 (operating at $5.87 \mathrm{~T}, 250$ $\mathrm{MHz}$ resonance of proton) spectrometers. Spectra were processed and analyzed with Mnova software (Mestrelab Research S.L.).

Determination of NMR Invisible Fractions (IF). The percentages of NMR IF shown in Table 1 were determined at $750 \mathrm{MHz}$. To this end, the integral of the ${ }^{1} \mathrm{H}$ NMR signals indicated in Table S1 was compared to that of an external reference (maleic acid or trimethylsilyl propionic acid placed in a coaxial capillary inside the NMR tube) in a series of quantitative ${ }^{1} \mathrm{H}$ NMR spectra recorded at increasing temperatures $(278,298,313,328$, and $343 \mathrm{~K})$. The IF\% at any T is defined as shown in Eq S1. IF figures lower than $1.5 \%$ were considered as zero.

$$
I F \%=\frac{\text { Integral at } 343 \mathrm{~K}-\text { Integral at a lower } \mathrm{T}}{\text { Integral at } 343 \mathrm{~K}} \times 100 \quad \mathrm{Eq} \mathrm{S} 1
$$


${ }^{1} \mathrm{H}$ NMR Data of the Polymers under Study (750 MHz, $\left.\mathrm{D}_{2} \mathrm{O}, 298 \mathrm{~K}\right) . \mathrm{CS}: \delta 2.07$ (s, Ac), 3.17 (br s, H2 GlcN), 3.35-4.42 (m, H2 GlcNAc, H3-H6). PLL: $\delta$ 1.40-1.59 (m, 2H, H4), 1.71-1.93 (m, 4H, H3, H5), 3.07 (t, J = 7.54 Hz, 2H, H6), 4.24-4.45 (m, 1H, H2). PVP: $\delta$ 1.50-1.89 (m, 2H, H1), 1.992.15 (m, 2H, H4), 2.27-2.63 (m, 2H, H5), 3.12-3.44 (m, 2H, H3), 3.55-3.99 (m, 1H, H2). PAA: $\delta$ 1.52-2.12 (m, 2H, H2), 2.32-2.63 (m, 1H, H1). Hyaluronic acid: $\delta 2.04$ (s, 3H, Ac), 3.22-4.15 (m, 10H, H2-H6 GlcA and GlcNAc), 4.47 (br s, 1H, H1 GlcA), 4.56 (br s, 1H, H1 GlcNAc). PGA: $\delta$ 1.90-2.14 (m, 2H, H2), 2.20-2.36 (m, 2H, H3), 4.34 (dd, J = 8.9, 5.4 Hz, 1H, H1). Pullulan: $\delta 3.48$ $(\mathrm{t}, \mathrm{J}=9.3 \mathrm{~Hz}, 1 \mathrm{H}), 3.58-3.66(\mathrm{~m}, 4 \mathrm{H}), 3.70(\mathrm{q}, \mathrm{J}=9.5 \mathrm{~Hz}, 2 \mathrm{H}), 3.80(\mathrm{~d}, \mathrm{~J}=9.3 \mathrm{~Hz}, 1 \mathrm{H}), 3.90(\mathrm{~d}, \mathrm{~J}$ $=8.1 \mathrm{~Hz}, 1 \mathrm{H}), 3.92-3.99(\mathrm{~m}, 5 \mathrm{H}), 4.03(\mathrm{t}, \mathrm{J}=9.3 \mathrm{~Hz}, 1 \mathrm{H}), 4.97(\mathrm{~d}, \mathrm{~J}=3.1 \mathrm{~Hz}, 1 \mathrm{H}), 5.39(\mathrm{dd}, \mathrm{J}=$ 18.3, 3.4 Hz, 1H). Carrageenan: $\delta$ 3.20-4.75 (m, 6H), 5.10 (s, 1H, H1-k), 5.29 (s, 1H, H1-i), 5.40 (s, 1H, H1-L). PSS: $\delta$ 0.50-2.33 (m, 3H, H1, H2), 5.96-6.96 (m, 2H, H3), 7.20-8.00 (m, 2H, H4). PMAA: $\delta$ 0.75-1.45 (m, 3H, H2), 1.48-2.25 (m, 2H, H1). Polyacrylamide: $\delta 1.40-1.90$ (m, 2H, H2), 2.10-2.50 (m, 1H, H1). PGA: $\delta$ 1.81-2.10 (m, 2H, H2), 2.20-2.42 (m, 2H, H3), 4.30-4.45 (m, 1H, H1). PEG: $\delta 3.50-3.88\left(\mathrm{~m}, \mathrm{CH}_{2} \mathrm{O}\right)$. PEI-branched: $\delta$ 0.97-3.75 (m, $\left.\mathrm{CH}_{2} \mathrm{~N}\right)$. PPI-G4: $\delta 1.43-1.53$ (m, H1), 1.61-1.75 (m, H4,7,10,13), 2.45-2.53 (m, H2,3,5,6,8,9,11), 2.54-2.59 (m, H12), 2.63-2.73 (m, H14). Ulvan: $\delta$ 1.25-1.36 (m, 3H, $\left.\mathrm{CH}_{3}\right)$ 3.20-4.90 (m, 11H, H1-H6). PVA: $\delta$ 1.36-2.20 (m, 2H, $\mathrm{H} 2), 3.50-4.15$ (m, 1H, H1). 
Invisible Fraction-Saturation Transfer Difference (IF-STD). IF-STD experiments were acquired at $750 \mathrm{MHz}$. The number of scans was 96, except for CS samples (128) and PPI-G4 (256). Unless otherwise mentioned, the inter-scan delay $\left(d_{1}\right)$ was $6 \mathrm{~s}$ immediately followed by a saturation time of $3 \mathrm{~s}$. The on- and off-saturation consisted of a train of low power saturation pulses of gaussian shape with nominal duration of $35.4 \mathrm{~ms}$ and separated by a $1 \mathrm{~ms}$ delay. The effective band-width of the saturation applied (BW ${ }^{\text {eff }}$ ) was $130 \mathrm{~Hz}$, a value that was determined experimentally in the spectrometer with a sucrose sample following the method described below. The frequency of the on-saturation was placed in an empty region of the ${ }^{1} \mathrm{H}$ spectrum, at a frequency $-1125 \mathrm{~Hz}$ from the right end (starting of noise) of the lowest ppm visible signal in the NMR spectrum of each polymer. This frequency is equivalent to $-1.5 \mathrm{ppm}$ in our spectrometer operating at $750 \mathrm{MHz}$. The frequency of the off-saturation was placed at $20 \mathrm{ppm}$, a position that is more than $10000 \mathrm{~Hz}$ away from any visible signal in all the ${ }^{1} \mathrm{H}$ spectra analyzed. STD off-on spectra were obtained with the scans corresponding to the $\mathrm{STD}_{\text {on }}$ and $\mathrm{STD}_{\text {off }}$ experiments interleaved during the acquisition and the corresponding FIDs subtracted automatically by the phase cycle. STD off control spectra were acquired by application of the off-saturation pulse train only, without any FID subtraction. STD factors were calculated from the integrals of the STD off-on and STD off spectra using equation S2.

$$
S \mathrm{TD} \%=\frac{\mathrm{STD}_{\text {off }}-\mathrm{STD}_{\text {on }}}{\mathrm{STD}_{\text {off }}} \times 100 \quad \mathrm{Eq} \mathrm{S} 2
$$

For this purpose, the two spectra were processed identically. Integration ranges of the polymer signals are shown in Table S1. STD factors lower than $0.05 \%$ were considered as zero. 
Table S1. Integration range of the polymer ${ }^{1} \mathrm{H}$ signals selected for IF-STD analysis and location of the on-saturation pulse.

\begin{tabular}{lcc}
\hline \multicolumn{1}{c}{ Polymer } & Integration range (ppm) & On-saturation \\
\hline Hyaluronic acid & $1.70-2.10$ & 0.36 \\
Carrageenan & $3.40-3.85$ & 1.92 \\
PSS & $0.05-2.20$ & -1.00 \\
Chitosan (CS) & $1.70-2.10$ & 0.54 \\
PVP & $1.39-1.92$ & -0.08 \\
PMAA & $0.50-1.40$ & -0.62 \\
Ulvan & $1.20-1.40$ & -0.35 \\
PAA & $1.00-1.95$ & 0.03 \\
Polyacrylamide & $1.00-2.70$ & -0.10 \\
Pullulan & $3.25-4.00$ & 1.85 \\
PVA & $1.00-2.00$ & 0.00 \\
PGA & $1.50-2.50$ & 0.38 \\
PLL & $0.70-1.70$ & -0.22 \\
PEG & $3.20-3.80$ & 2.00 \\
PEI-branched & $2.20-2.90$ & 0.22 \\
PPI-G4 & $1.40-1.50(\mathrm{H} 1)$ & \\
& $1.55-1.82(\mathrm{H} 4,7,10,13)$ & 0.06 and 4.16 \\
& $2.40-2.48(\mathrm{H} 2,3,5,6,8,9,11)$ & \\
& $2.48-2.57(\mathrm{H} 12)$ & \\
& $2.57-2.67(\mathrm{H} 14)$ & \\
& & \\
& & \\
& &
\end{tabular}




\section{Experimental Determination of the Effective Band-width (BW $W^{\text {eff }}$ Covered by the Saturation in}

an IF-STD Experiment. BW ${ }^{\text {eff }}$ (in $\mathrm{Hz}$ ) depends on several experimental parameters, including the shape of the pulse, its nominal duration and power level, the inter-pulse delay used in the saturation train as well as the spectrometer hardware (RF amplifier and probe). In this section, a method is proposed for measuring $\mathrm{BW}^{\mathrm{eff}}$ in any modern spectrometer (year 2000 and beyond). The method measures $\mathrm{STD}_{\text {off-on }}$ and $\mathrm{STD}_{\text {off }}$ experiments of a sample of $50 \mathrm{mM}$ sucrose in $\mathrm{D}_{2} \mathrm{O}$ under analogue conditions to those described above for the measurement of the IF-STD spectra of polymers, except for those parameters mentioned below. The number of scans was 64 . The on-saturation was placed at $3.737 \mathrm{ppm}$, corresponding to the overlapping signals of two methylene protons that are assigned to H6g and H6f of sucrose. Fourteen pairs of STD spectra (STD off-on and STD off) were measured at a series of pulse-lengths for the shaped gaussian pulse used for the saturation. The gaussian pulse is repeated during the saturation train to cover the same total saturation time of $1 \mathrm{~s}$ in each experiment. The nominal durations explored for the gaussian pulse were 14.1, 15.1, 16.3, 17.7, $19.3,21.2,26.5,28.3,30.3,32.6,35.4,38.6,42.4$, and $50 \mathrm{~ms}$. In each case, the RF power of the gaussian pulse was set to produce the same tilt angle of $90^{\circ}$. This power was calculated based on the reference of the hard $90^{\circ}$ proton pulse by using the ShapeTool/Pandora's box module included in the TopSpin/VNMRJ control software. The same software was used to calculate the theoretical excitation band-width in $\mathrm{Hz}$ covered by the gaussian shaped pulse $\left(\mathrm{BW}^{\text {calc }}\right)$. The two mentioned calculations assume a linear response in the power of the RF proton amplifier of the spectrometer, a requirement fulfilled by modern spectrometers equipped with linear RF amplifiers, which can be even improved by the experimental correction of the linearization that is done during the spectrometer's installation.

For small molecules in solution, as sucrose in $\mathrm{D}_{2} \mathrm{O}$, at the typical frequencies of the NMR spectrometers, the subtracted $\mathrm{STD}_{\text {off-on }}$ spectrum shows the highest intensity for the peak/s that 
is/are being affected by the saturation. In the same spectrum, the presence of NOE peaks that denote proton-proton proximity are of very low intensity (a few percent of the saturated peak/s) and can be easily identified as they appear with opposite sign respect to the peak/s that is/are being saturated. Other possible peaks are those generated by spin-diffusion phenomena (three spin effects), which may have the same sign that the saturated peak/s but their intensity is very modest and comparable to that of the NOE. The remaining peaks are those that are neither affected by the saturation, NOE or spin-diffusion; they will appear with null intensity in the STD off-on spectrum. Under these premises, it is straightforward to distinguish in a STD off-on spectrum of sucrose the peak/s that is/are being affected by the on-saturation, and to determine experimentally an upper and lower limit values of $\mathrm{BW}^{\text {eff }}$ by measuring the distance in $\mathrm{Hz}$ from the central frequency position at which the on-saturation is applied to (a) the furthest peak identified as saturated (lower limit,

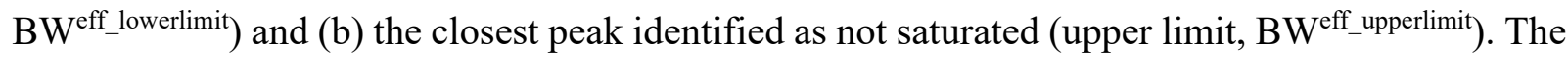
lower and upper limits of $\mathrm{BW}^{\text {eff }}$ were measured for sucrose using the above series of gaussian saturation pulse-lengths in a Bruker NEO $750 \mathrm{MHz}$ spectrometer (Figure S1). The results obtained are given in Table S2. Figure S2 represents BW ${ }^{\text {calc }}$, this is the excitation band-width calculated with the spectrometer software, and the experimentally determined BW ${ }^{\text {eff_lowerlimit }}$ and BW ${ }^{\text {eff_upperlimit }}$ at each pulse-length. As a linear relationship can be expected between $\mathrm{BW}^{\text {calc }}$ and $\mathrm{BW}^{\mathrm{eff}}$, the points were fitted to a straight line so that at each pulse-length, the value of $\mathrm{BW}^{\text {eff }}$ passes in between $\mathrm{BW}^{\text {eff_lowerlimit }}$ and BW $\mathrm{Bff}_{\text {efupperlimit }}$. Such a linear dependence provides $\mathrm{BW}^{\text {eff_fit }}$ that is equivalent to $\mathrm{BW}^{\text {eff }}$ in the IF-STD experiment (Figure S2 and Table S2). According to these results, under our experimental conditions, the $\mathrm{BW}^{\text {eff }}$ at each pulse-length corresponds to twice the value of that calculated by BW $\mathrm{BW}^{\text {calc }}$ in the Bruker NEO $750 \mathrm{MHz}$ spectrometer. Under identical experimental conditions, a BW ${ }^{\text {calc }}$ equal to $\mathrm{BW}^{\text {eff }}$ was obtained for the Varian INOVA $750 \mathrm{MHz}$ spectrometer. 


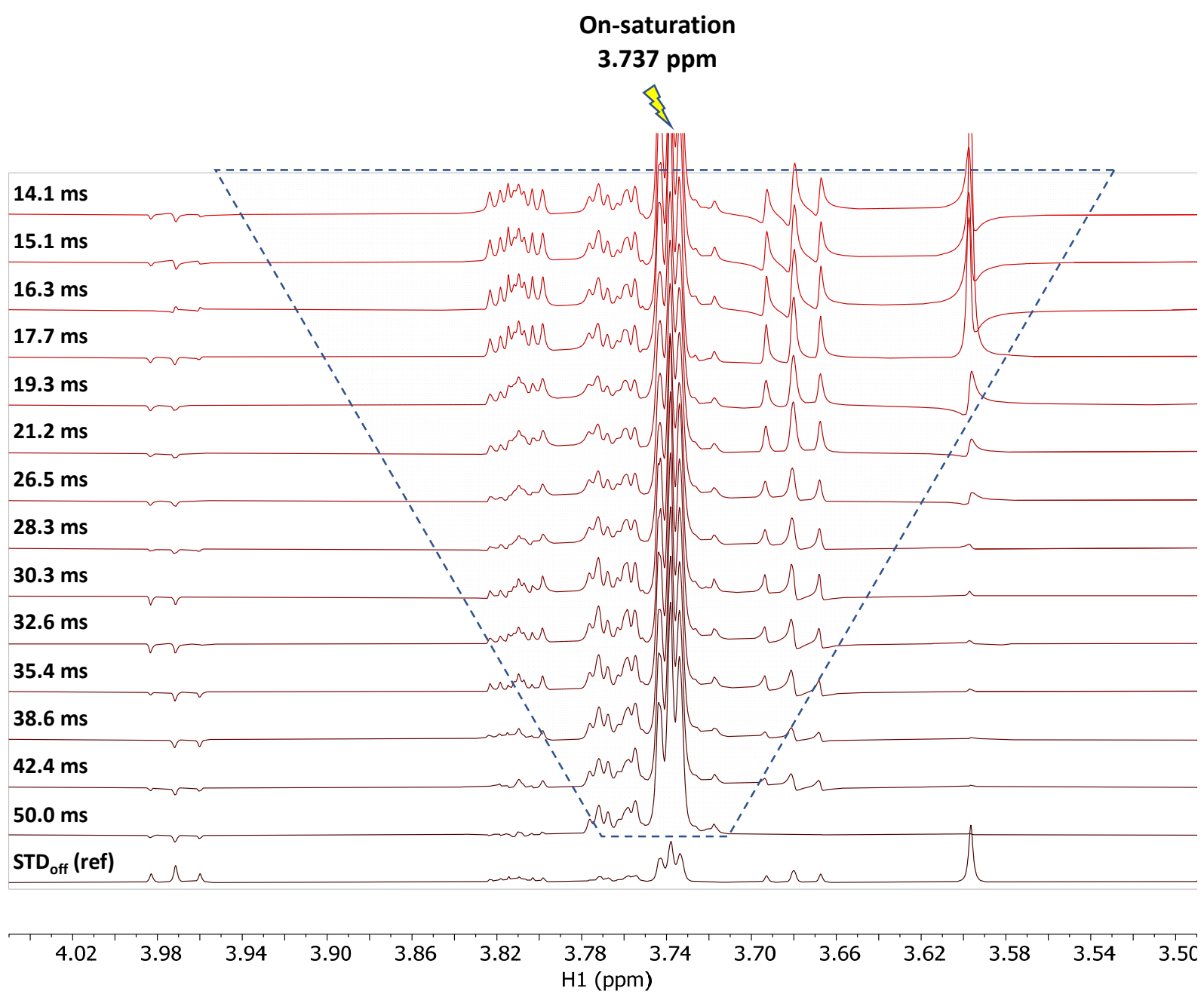

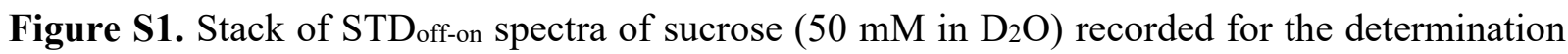
of the experimental effective band-width (BW ${ }^{\text {eff }}$ ) for the IF-STD experiment in our Bruker NEO $750 \mathrm{MHz}$ spectrometer. The nominal duration of the gaussian saturation pulses (in ms) is indicated. The position of the on-saturation at $3.737 \mathrm{ppm}$ is shown by an arrow. At the bottom is the STD off $_{\text {f }}$ spectrum (reference). In each $\mathrm{STD}_{\text {off-on }}$ spectrum the distance between the pair of stripped lines (in $\mathrm{Hz}$ ) corresponds to the $\mathrm{BW}^{\text {eff_fit }}$ shown in Table S2. 
Table S2. Determination of the experimental effective band-width (BW ${ }^{\text {eff }}$ ) of the IF-STD experiment in our Bruker NEO $750 \mathrm{MHz}$ spectrometer. BW ${ }^{\text {eff_lowerlimit }}$ and BW eff_upperlimit $_{\text {were }}$ determined experimentally in $\mathrm{STD}_{\text {off-on }}$ spectra of sucrose $\left(50 \mathrm{mM}\right.$ in $\left.\mathrm{D}_{2} \mathrm{O}\right)$ recorded with a series of gaussian saturation pulse-lengths. $\mathrm{BW}^{\text {calc }}$ is the excitation band-width calculated with the Bruker Shapetool module of TopSpin at each gaussian-pulse length. BW ${ }^{\text {eff-fit }}$ is the value obtained by fitting the points of Figure S2 to a straight line.

\begin{tabular}{|c|c|c|c|c|}
\hline $\begin{array}{c}\text { Gaussian pulse } \\
\text { length }{ }^{\text {(a) }} \\
\text { (ms) }\end{array}$ & $\begin{array}{c}\text { BW } \\
(\mathrm{Hz})\end{array}$ & $\begin{array}{c}\text { BW } \\
\text { (Hz__lowerlimit } \\
\text { (Hz) }\end{array}$ & $\begin{array}{c}\text { BW } \\
\text { eff_upperlimit } \\
\text { (Hz) }\end{array}$ & $\begin{array}{c}\text { BW } \\
\text { (Hz) }\end{array}$ \\
\hline 50 & 42.44 & 62 & 88 & 84.88 \\
\hline 42.4 & 50 & 114 & 128 & 100 \\
\hline 38.6 & 55 & 114 & 128 & 110 \\
\hline 35.4 & 60 & 112 & 220 & 120 \\
\hline 32.6 & 65 & 112 & 220 & 130 \\
\hline 30.3 & 70 & 112 & 220 & 140 \\
\hline 28.3 & 75 & 112 & 220 & 150 \\
\hline 26.5 & 80 & 112 & 220 & 160 \\
\hline 21.2 & 100 & 112 & 220 & 200 \\
\hline 19.3 & 110 & 112 & 220 & 220 \\
\hline 17.7 & 120 & 218 & 330 & 240 \\
\hline 16.3 & 130 & 218 & 330 & 260 \\
\hline 15.1 & 140 & 218 & 330 & 280 \\
\hline 14.1 & 150 & 218 & 330 & 300 \\
\hline
\end{tabular}

(a) Nominal duration of the gaussian pulses used for the saturation. The RF power of the pulses was calibrated to produce a tilt angle of $90^{\circ}$. 


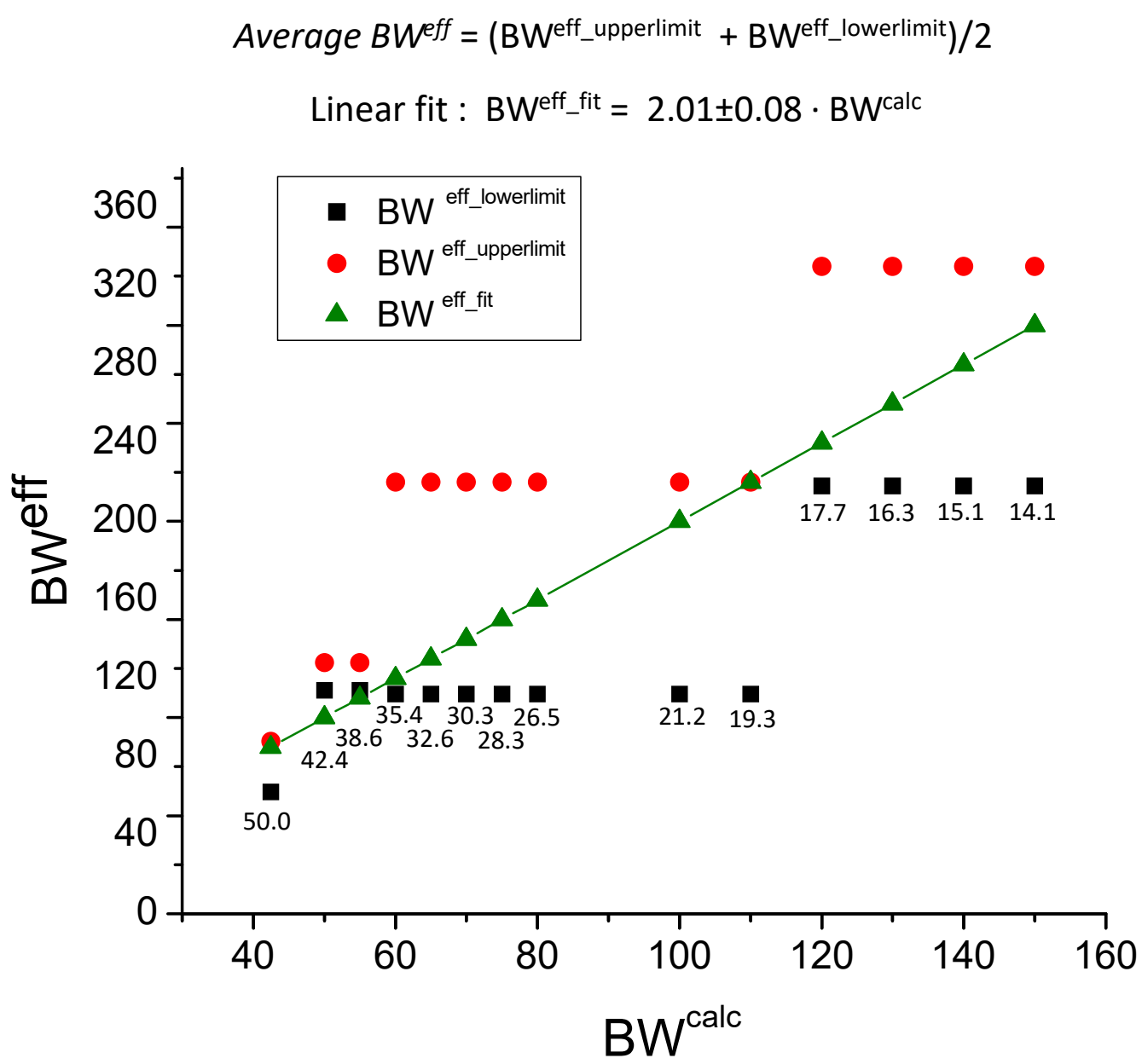

Figure S2. Plot of BW ${ }^{\text {calc }}$ respect to the measured BW ${ }^{\text {eff_lowerlimit }}$ (black squares) and BW ${ }^{\text {eff_upperlimit }}$ (red circles) for sucrose $\left(50 \mathrm{mM}\right.$ in $\left.\mathrm{D}_{2} \mathrm{O}\right)$ in our Bruker NEO $750 \mathrm{MHz}$ spectrometer. At each value of $\mathrm{BW}^{\text {calc }}$ the numbers indicate the corresponding pulse-length of the gaussian pulse used in ms. As there is a linear relationship between $\mathrm{BW}^{\mathrm{calc}}$ and $\mathrm{BW}^{\mathrm{eff}}$, the points were fitted to a straight line that passes in between $\mathrm{BW}^{\text {eff_lowerlimit }}$ and $\mathrm{BW}^{\text {eff_upperlimit }}$ at each pulse-length (green triangles).

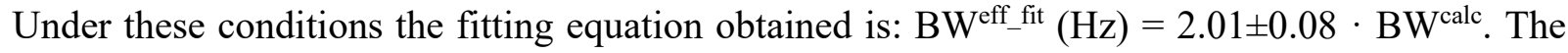
fitting provides $\mathrm{BW}^{\text {eff-fit }}$ which corresponds to the actual BW ${ }^{\text {eff }}$ in IF-STD experiments. 
Determination of ${ }^{1} \boldsymbol{H} \boldsymbol{T}_{2}$ Relaxation Times. ${ }^{1} \mathrm{H} T_{2}$ values were determined at $500 \mathrm{MHz}$ using the Carr-Purcell-Meiboom-Gill $(\mathrm{CPMG})^{3}$ pulse sequence $\left[90^{0} \mathrm{x}-\left(\tau-180^{0} \mathrm{y}-\tau\right)_{n}\right.$, where $2 \tau$ is a fixed echo time ( $\tau=0.7 \mathrm{~ms}), n$ is the number of echoes, and the total CPMG duration $(t)$ is given by $2 \tau \cdot n$. The CPMG duration $(t)$ was linearly varied along 16 steps between a minimum value of $1.4 \mathrm{~ms}(n$ $=1$ ) and a maximum of ca. 6 to 7 times the highest $T_{2}$. At each step, a spectrum was acquired with 64 scans. The interscan relaxation delay $\left(d_{l}\right)$ was larger than 5 times the highest ${ }^{1} \mathrm{H} T_{1}$ in the sample. The absolute signal integral $(I)$ at each value of $t$ was fitted to the mono-exponential equation S3 to determine the relaxation time $T_{2}$ :

$$
I(t) / I_{0}=\exp \left(-t / T_{2}\right) \quad \text { Eq S3 }
$$

where $I(t)$ and $I_{0}$ are the observed signal integrals at a certain value of $t$ and for $t$ equal to the minimum value of the series $(t=1.4 \mathrm{~ms}$ ), respectively. OriginPro 9.0 Software (Originlab Corporation) was used to perform the exponential fittings to obtain the ${ }^{1} \mathrm{H}$ relaxation times $T_{2}$.

Determination of ${ }^{1} \mathrm{H} T_{2}$ values at the visible-invisible interphase of polymers was performed by means of an IF-STD-CPMG experiment. This hybrid pulse sequence was built with a $T_{2}$ filter based on the conventional CPMG sequence. ${ }^{3}$ The experimental conditions used for STD off $^{-C P M G}$

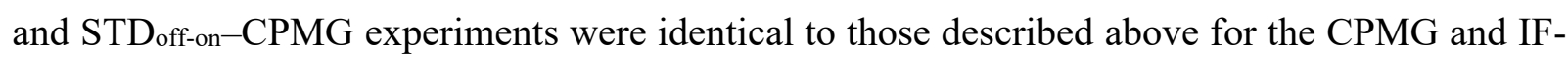
STD experiments, using 64 scans.

Determination of Translational Diffusion Coefficients. Translational diffusion coefficients (D) were measured at $750 \mathrm{MHz}$ with the BPPSTE experiment based on the stimulated echo and bipolar pulse field gradients (PFG) (sequences Doneshot in the Agilent and ledbpgp2s in the Bruker pulse sequence libraries, respectively). ${ }^{4}$ The PFG strength was calibrated with a reference sample of $\mathrm{D}_{2} \mathrm{O}$ $99.9 \%$ at $298 \mathrm{~K}, \mathrm{D}=1.87 \cdot 10^{-9} \mathrm{~m}^{2} \mathrm{~s}^{-1}$. For the measurements with polymers, the diffusion delay was 
set to $3 \mathrm{~s}$, the duration $\delta$ of the PFG encoding diffusion was set to $4 \mathrm{~ms}$. The strength of the PFG was linearly varied between 4 and $58 \mathrm{G} \cdot \mathrm{cm}^{-1}$ along 20 steps, each one with acquisition of an FID. Diffusion coefficients were determined by analysis of the signal integrals along the 20 spectra and non-linear fitting to the Stejskal-Tanner equation governing the integral attenuation in the experiment.

Determination of diffusion values was also performed with an IF-STD-BPPSTE experiment that used identical parameters. The later pulse sequence was built by incorporating the IF-STD scheme and the parameters described above to the conventional BPPSTE pulse sequence. 
3. IF-STD Spectra and Figures

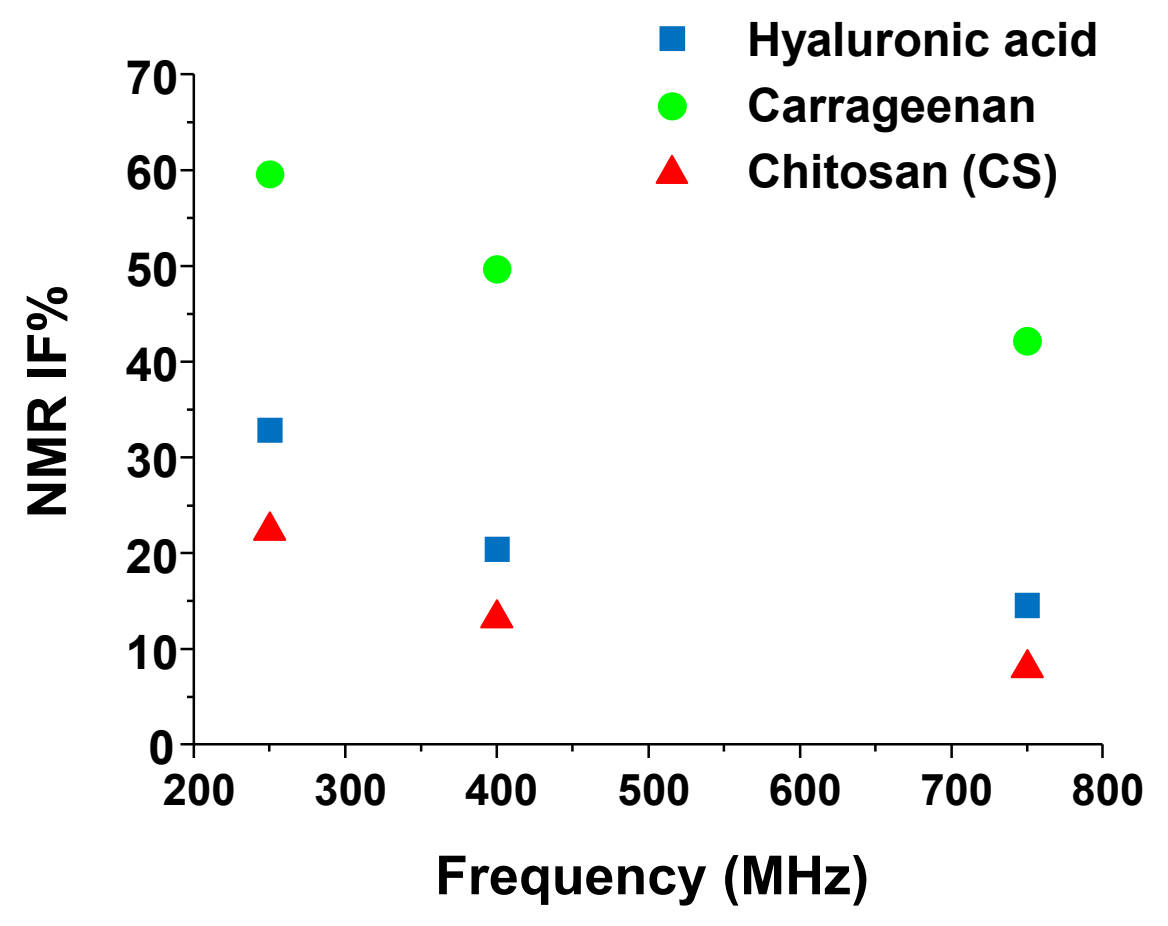

Figure S3. ${ }^{1} \mathrm{H}$ NMR IF of CS, hyaluronic acid and carrageenan at three magnetic fields $(250,400$ and $750 \mathrm{MHz})$. Hyaluronic acid and carrageenan dissolved in $\mathrm{D}_{2} \mathrm{O}(10 \mathrm{mg} / \mathrm{mL}), \mathrm{CS}$ in $350 \mathrm{mM}$ $\mathrm{CD}_{3} \mathrm{CO}_{2} \mathrm{D} / 135 \mathrm{mM} \mathrm{NaOD}$ in $\mathrm{D}_{2} \mathrm{O}(10 \mathrm{mg} / \mathrm{mL})$. 


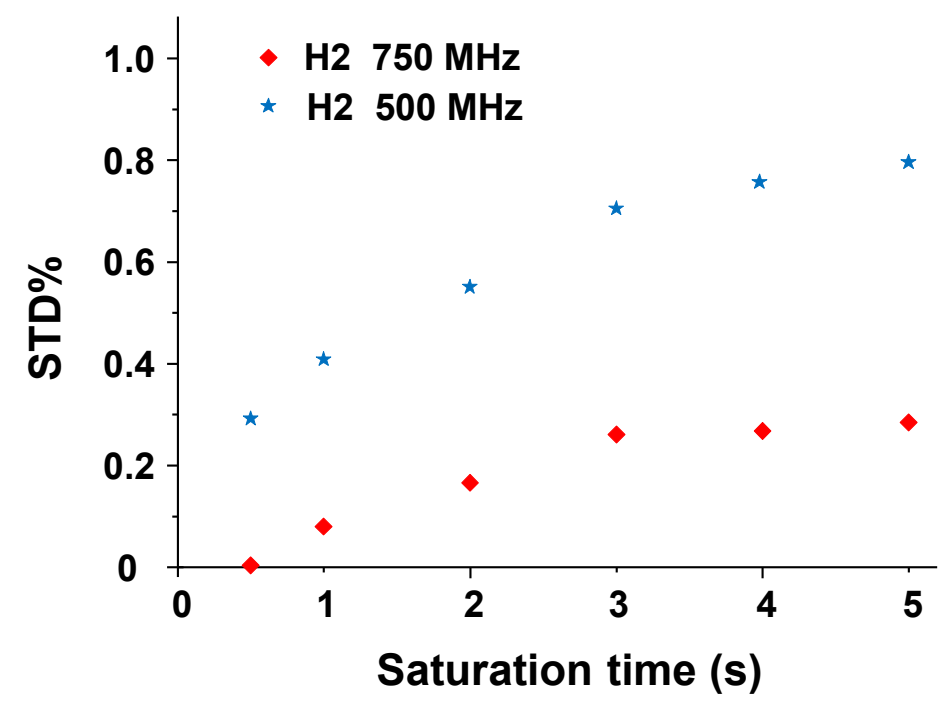

Figure S4. STD factor as a function of the saturation time (on-saturation at $0.54 \mathrm{ppm}$ ) and magnetic field (500 and $750 \mathrm{MHz}$ ) for the H2 of CS (80 kDa, DA 14) dissolved at $10 \mathrm{mg} / \mathrm{mL}$ in $350 \mathrm{mM}$ $\mathrm{CD}_{3} \mathrm{CO}_{2} \mathrm{D} / 135 \mathrm{mM} \mathrm{NaOD}$ in $\mathrm{D}_{2} \mathrm{O}$.
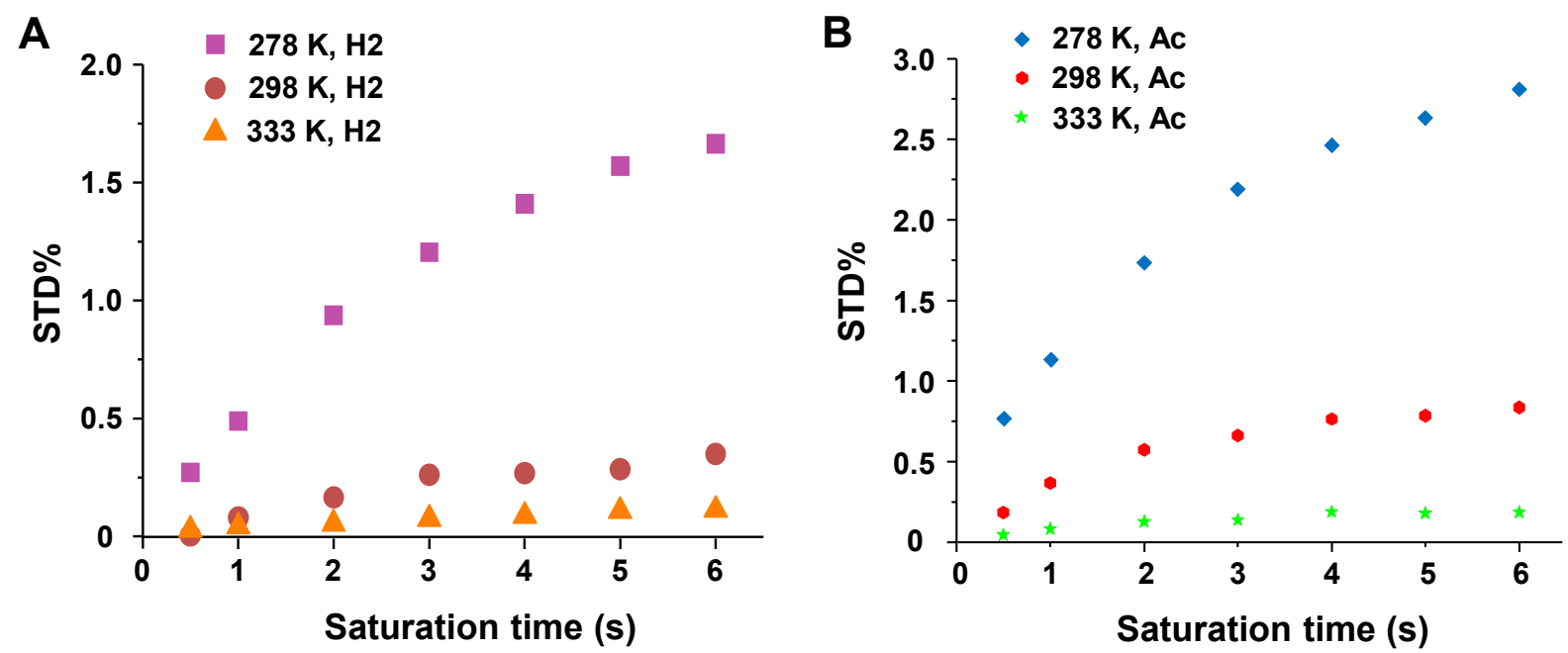

Figure S5. STD factor as a function of the saturation time (on-saturation at $0.54 \mathrm{ppm}$ ) and temperature (278, 298 and $333 \mathrm{~K})$ for the H2 (A) and acetyl (B) of CS (80 kDa, DA 14) dissolved at $10 \mathrm{mg} / \mathrm{mL}$ in $350 \mathrm{mM} \mathrm{CD}{ }_{3} \mathrm{CO}_{2} \mathrm{D} / 135 \mathrm{mM} \mathrm{NaOD}$ in $\mathrm{D}_{2} \mathrm{O}$. 


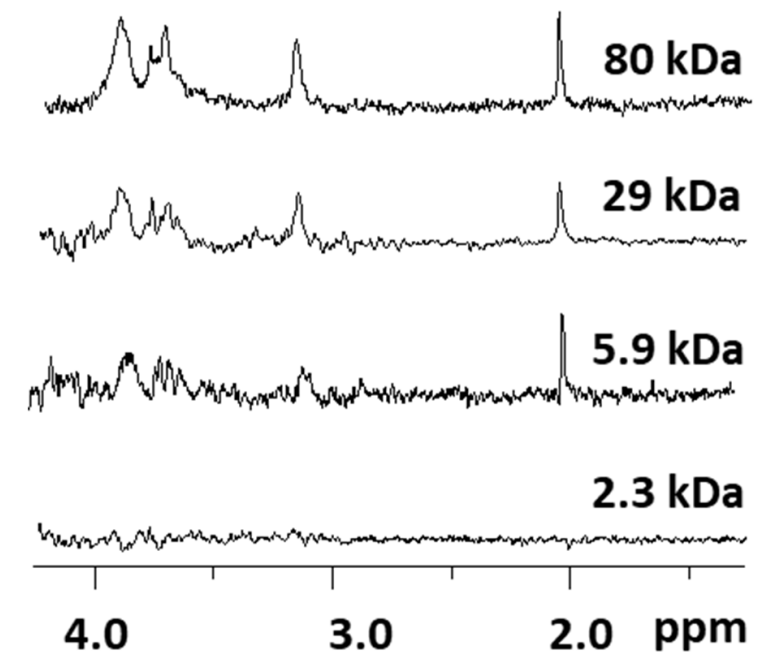

Figure S6. Effect of the MW of CS on the IF-STD intensity: STD off-on spectra $(750 \mathrm{MHz}, 298 \mathrm{~K}$, on-saturation at $0.54 \mathrm{ppm}$, saturation time $3 \mathrm{~s})$ of CS $(2.3-80 \mathrm{kDa}, 10 \mathrm{mg} / \mathrm{mL}$ in $\mathrm{pD} 4.5$ acetate buffer, $\mathrm{D}_{2} \mathrm{O}$ ). Vertical scale of $\mathrm{STD}_{\text {off-on }}$ spectra is shown $100 \times$.

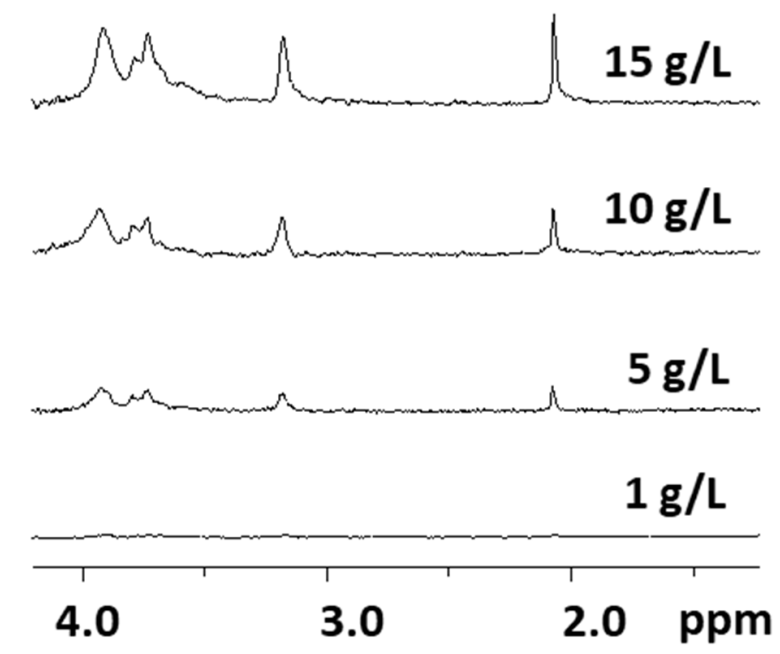

Figure S7. Effect of the concentration of CS on the IF-STD intensity: STD off-on spectra $(750 \mathrm{MHz}$, $298 \mathrm{~K}$, on-saturation at $0.54 \mathrm{ppm}$, saturation time $3 \mathrm{~s})$ of CS $(80 \mathrm{kDa}, 1-15 \mathrm{mg} / \mathrm{mL}$ in pD 4.5 acetate buffer, $\mathrm{D}_{2} \mathrm{O}$ ). Vertical scale of $\mathrm{STD}_{\text {off-on }}$ spectra is shown $100 \times$. 

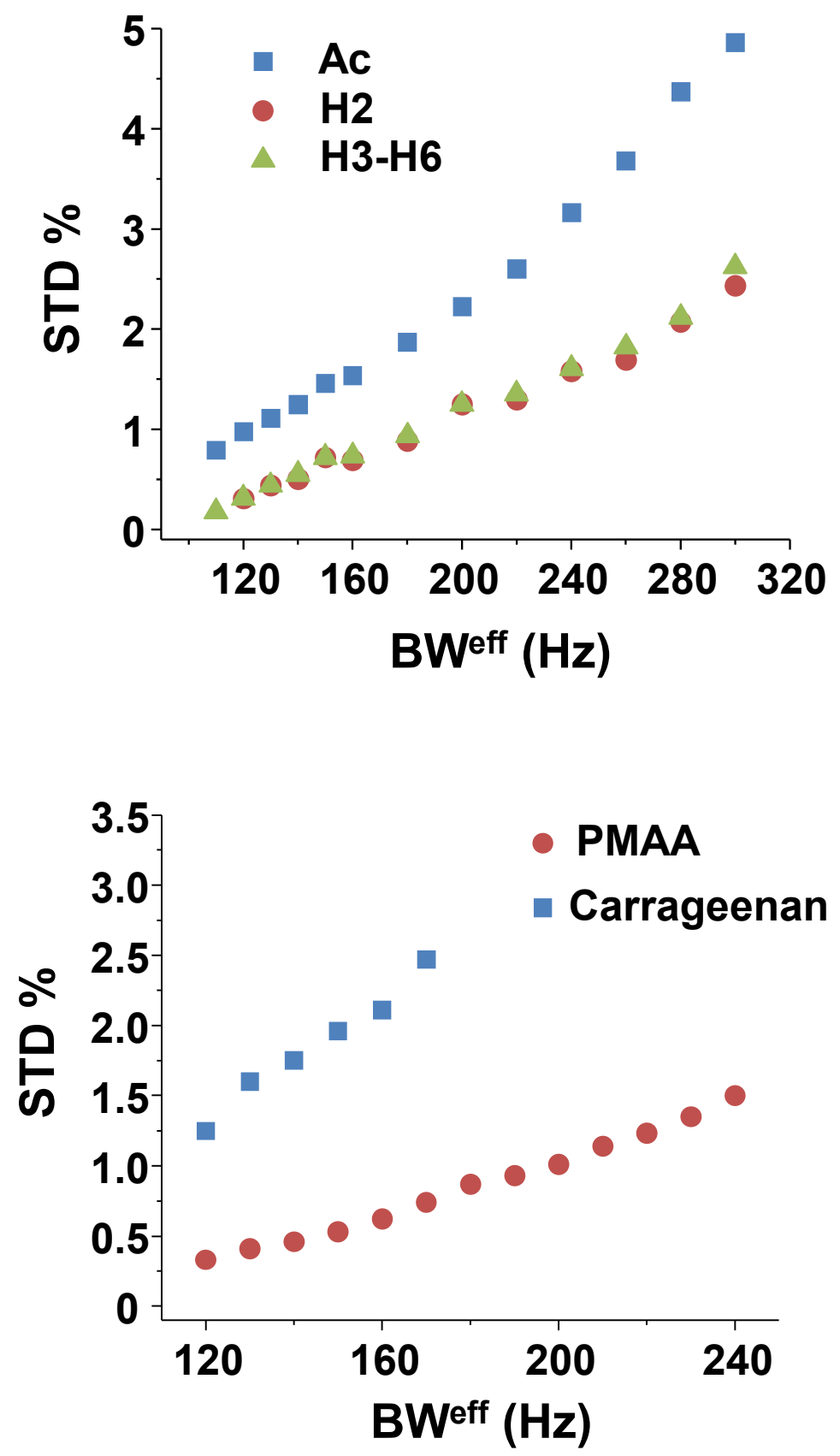

Figure S8. STD factors ( $750 \mathrm{MHz}, 298 \mathrm{~K}$, saturation time $3 \mathrm{~s}$ ) as a function of the effective bandwidth (BW ${ }^{\text {eff }}$ ) for $\mathrm{CS}\left(80 \mathrm{kDa}, \mathrm{DA} 14,10 \mathrm{mg} / \mathrm{mL}\right.$ in $\mathrm{D}_{2} \mathrm{O}$, on-saturation at $\left.0.54 \mathrm{ppm}\right)$, PMAA (30 $\mathrm{kDa}, 10 \mathrm{mg} / \mathrm{mL}$ in $\mathrm{D}_{2} \mathrm{O}$, on-saturation at $\left.-0.62 \mathrm{ppm}\right)$, and carrageenan $\left(647 \mathrm{kDa}, 10 \mathrm{mg} / \mathrm{mL}\right.$ in $\mathrm{D}_{2} \mathrm{O}$, on-saturation at $1.92 \mathrm{ppm})$. 


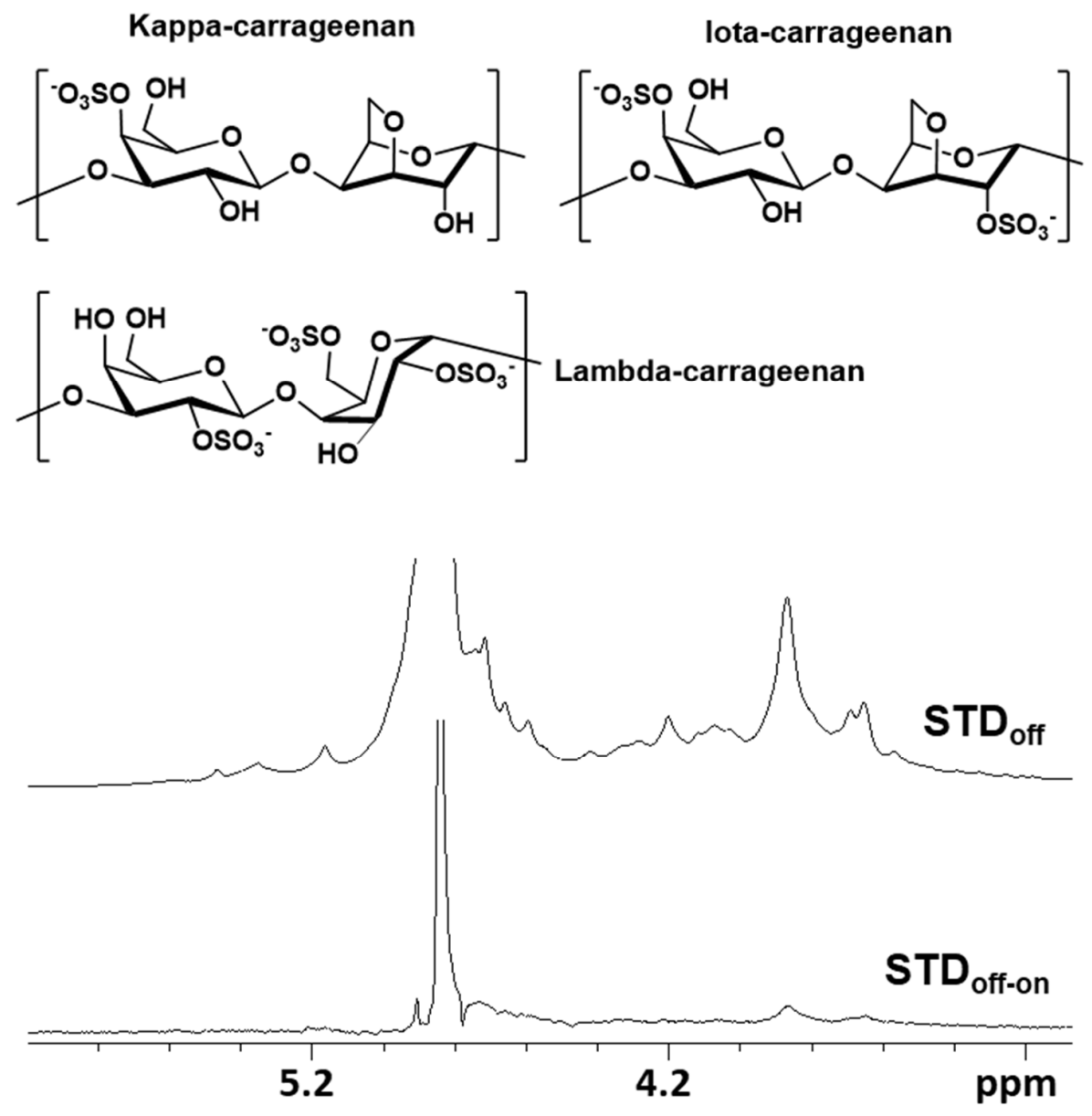

Figure S9. IF-STD spectra (750 MHz, $298 \mathrm{~K}$, on-saturation at $1.92 \mathrm{ppm}$, saturation time $3 \mathrm{~s}$ ) of

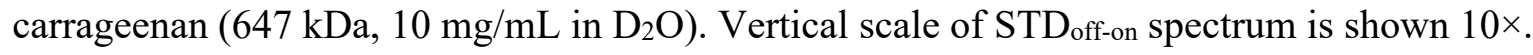




\section{Ulvan}
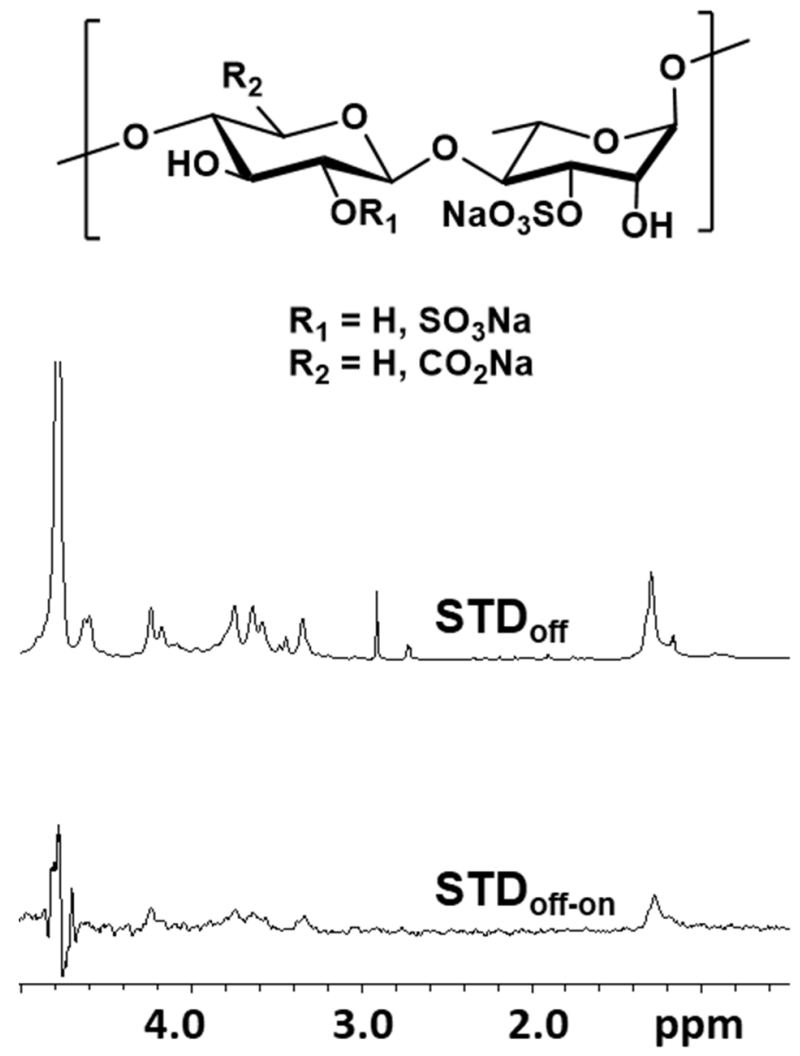

Figure S10. IF-STD spectra (750 MHz, $298 \mathrm{~K}$, on-saturation at $-0.35 \mathrm{ppm}$, saturation time $3 \mathrm{~s})$ of ulvan $\left(524 \mathrm{kDa}, 10 \mathrm{mg} / \mathrm{mL}\right.$ in $\left.\mathrm{D}_{2} \mathrm{O}\right)$. Vertical scale of $\mathrm{STD}_{\text {off-on }}$ spectrum is shown $100 \times$. 


\section{Poly(acrylic acid) (pD 7)}
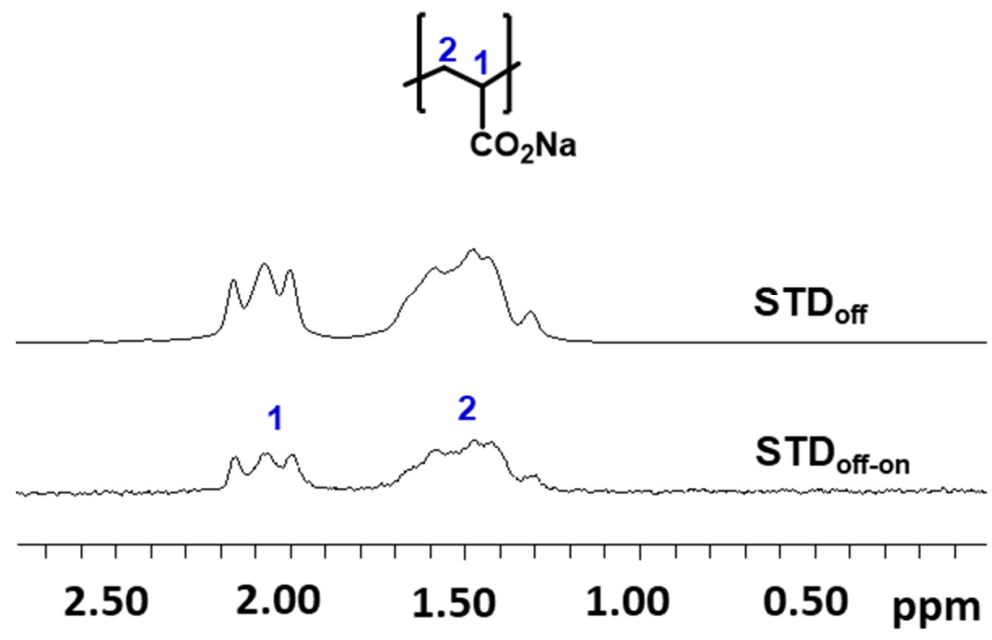

Figure S11. IF-STD spectra (750 MHz, $298 \mathrm{~K}$, on-saturation at $0.03 \mathrm{ppm}$, saturation time $3 \mathrm{~s}$ ) of poly(acrylic acid) (PAA $450 \mathrm{kDa}, 10 \mathrm{mg} / \mathrm{mL}$ in $\mathrm{D}_{2} \mathrm{O}, \mathrm{pD} 7$ ). Vertical scale of $\mathrm{STD}_{\text {off-on }}$ spectrum is shown $10 \times$. 
Poly(acrylic acid) (pD 3)

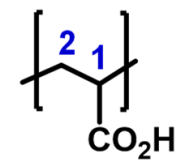

STD $_{\text {off-on }} \quad 343 \mathrm{~K}$
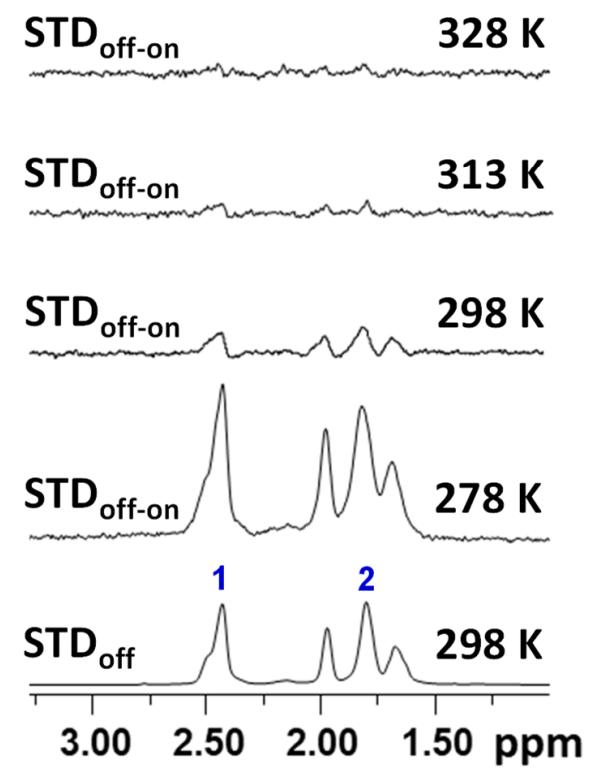

Figure S12. Effect of the temperature on the STD intensity: IF-STD spectra (750 MHz, 278-343 $\mathrm{K}$, on-saturation at $0.03 \mathrm{ppm}$, saturation time $3 \mathrm{~s}$ ) of poly(acrylic acid) (PAA $450 \mathrm{kDa}, 10 \mathrm{mg} / \mathrm{mL}$ in $\mathrm{D}_{2} \mathrm{O}, \mathrm{pD} 3$ ). Vertical scale of $\mathrm{STD}_{\text {off-on }}$ spectra is shown $200 \times$. 


\section{Poly(ethylene glycol)}
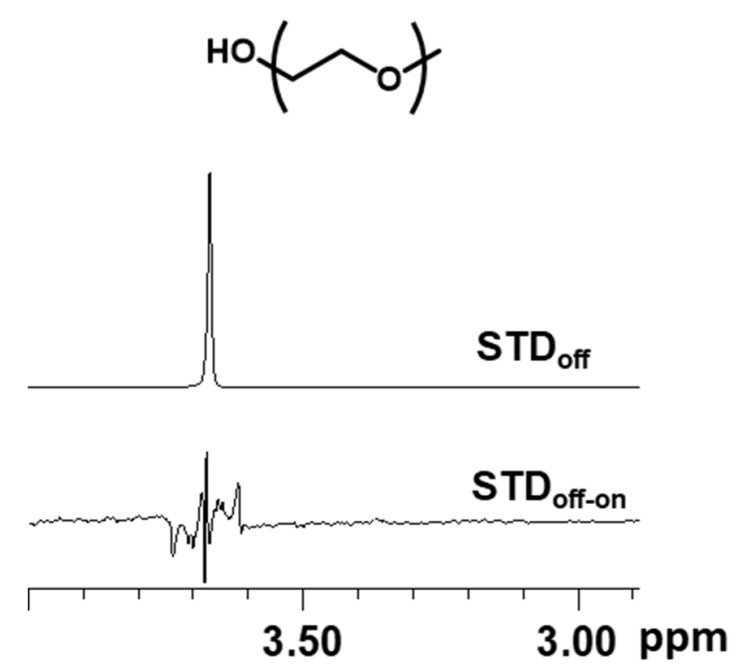

Figure S13. IF-STD spectra $(750 \mathrm{MHz}, 298 \mathrm{~K}$, on-saturation at $2.00 \mathrm{ppm}$, saturation time $3 \mathrm{~s}$ ) of poly(ethylene glycol) (PEG $10 \mathrm{kDa}, 10 \mathrm{mg} / \mathrm{mL}$ in $\mathrm{D}_{2} \mathrm{O}$ ). Vertical scale of $\mathrm{STD}_{\text {off-on spectrum is }}$ shown $15 \times$. 


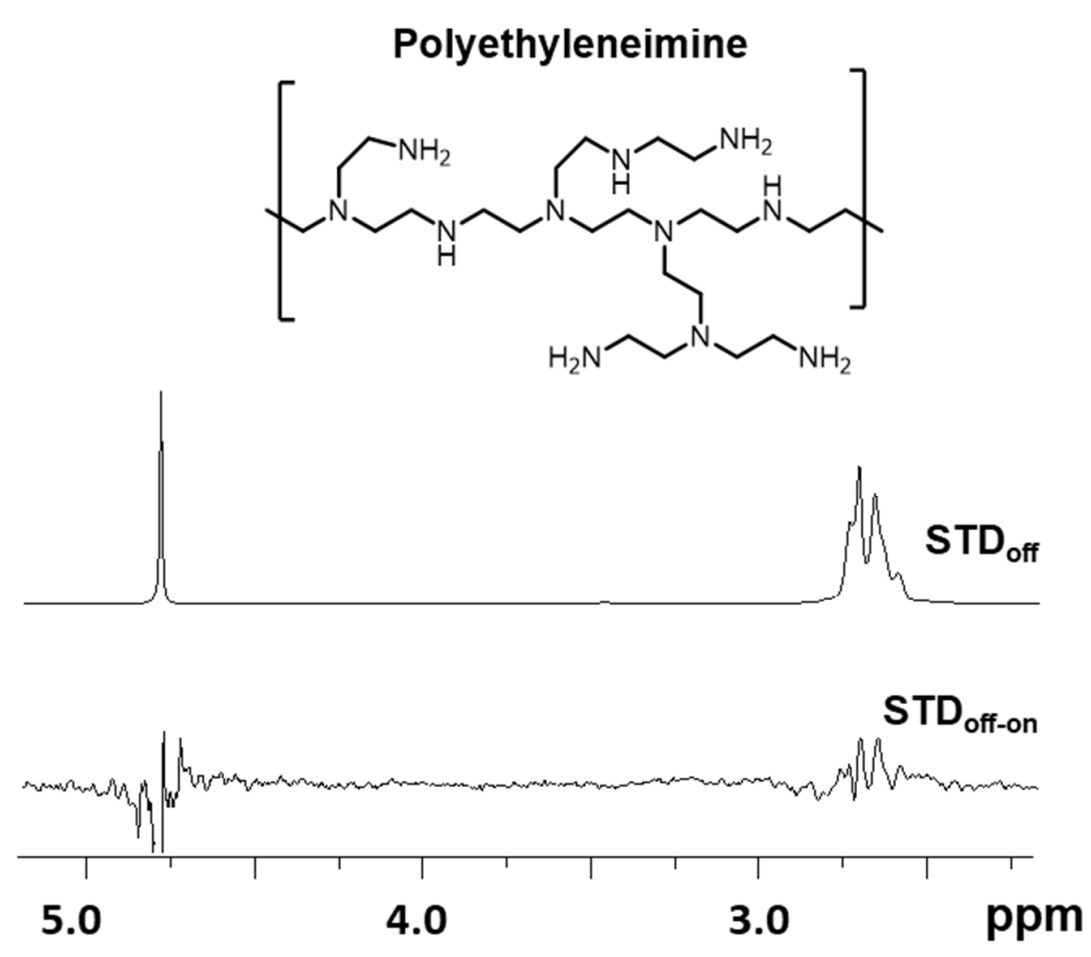

Figure S14. IF-STD spectra (750 MHz, $298 \mathrm{~K}$, on-saturation at $0.22 \mathrm{ppm}$, saturation time $3 \mathrm{~s}$ ) of branched polyethyleneimine (PEI-branched $25 \mathrm{kDa}, 10 \mathrm{mg} / \mathrm{mL}$ in $\mathrm{D}_{2} \mathrm{O}$ ). Vertical scale of STD offon spectrum is shown $100 \times$. 


\section{Poly-L-glutamic acid}
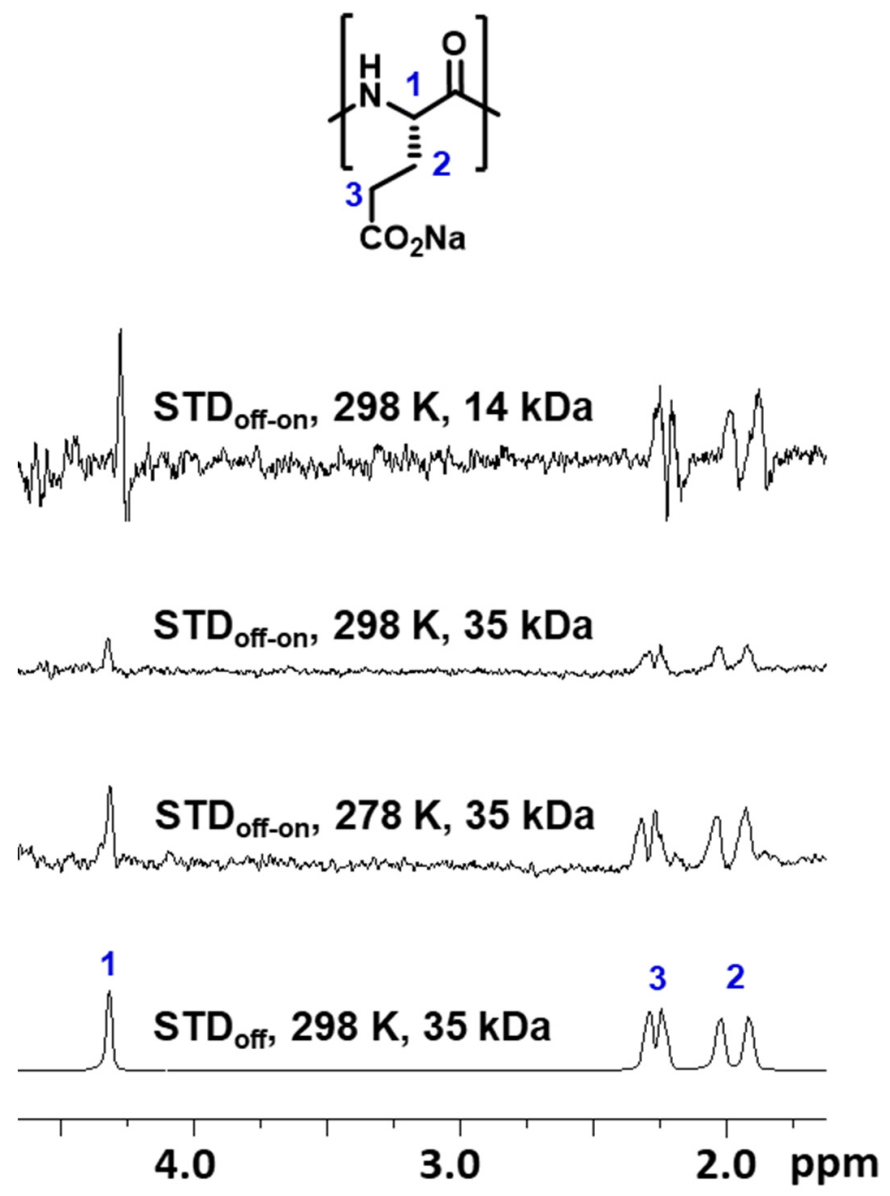

Figure S15. Effect of the MW and temperature on the STD intensity: IF-STD spectra $(750 \mathrm{MHz}$, 278 and $298 \mathrm{~K}$, on-saturation at $0.38 \mathrm{ppm}$, saturation time $3 \mathrm{~s}$ ) of poly-L-glutamic acid sodium salt

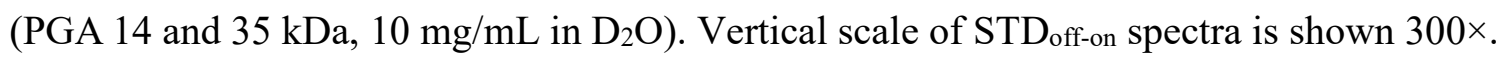




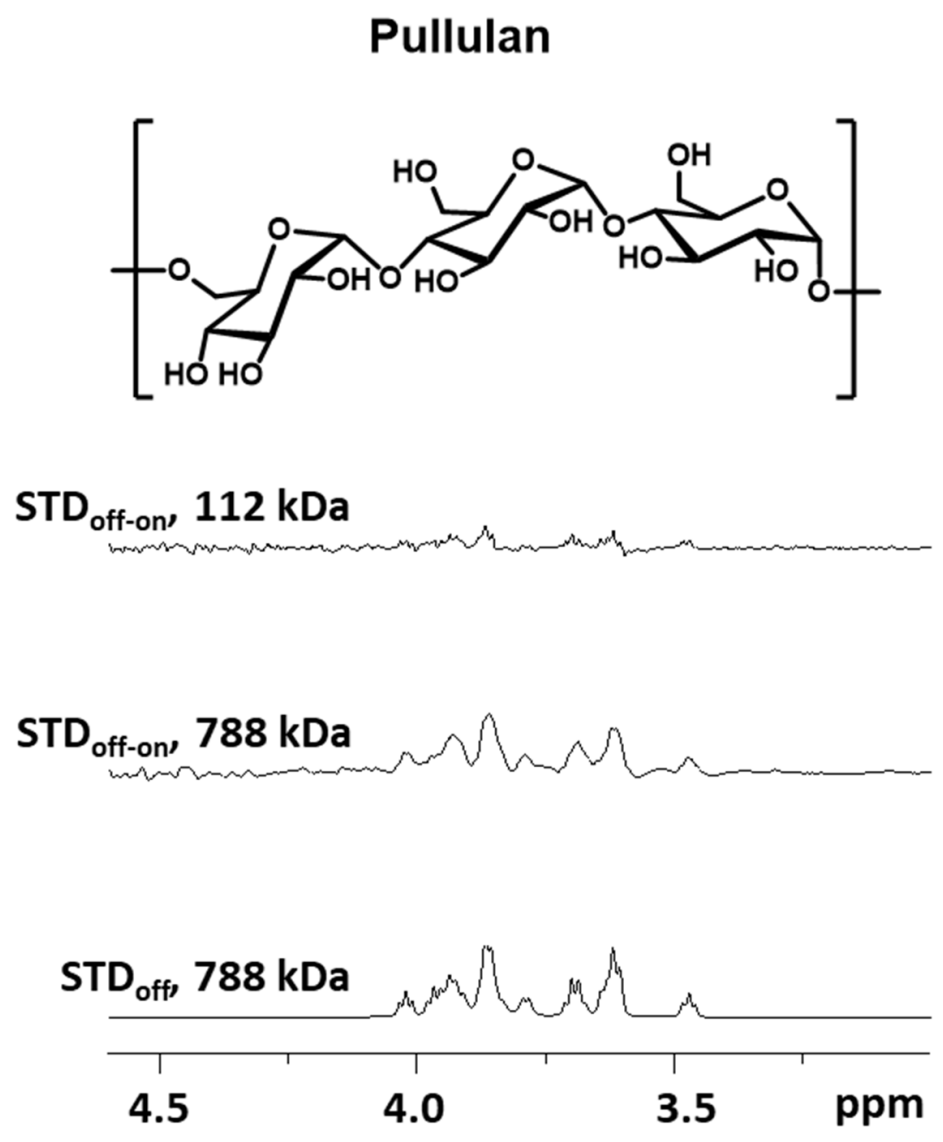

Figure S16. Effect of the MW on the STD intensity: IF-STD spectra (750 MHz, $298 \mathrm{~K}$, onsaturation at $1.85 \mathrm{ppm}$, saturation time $3 \mathrm{~s})$ of pullulan (112 and $788 \mathrm{kDa}, 10 \mathrm{mg} / \mathrm{mL}$ in $\left.\mathrm{D}_{2} \mathrm{O}\right)$. Vertical scale of STD off-on spectra is shown $100 \times$. 


\section{Poly(vinyl alcohol)}<smiles>CC(C)(C)CC(O)C1CCC1CC(C)(C)C</smiles>
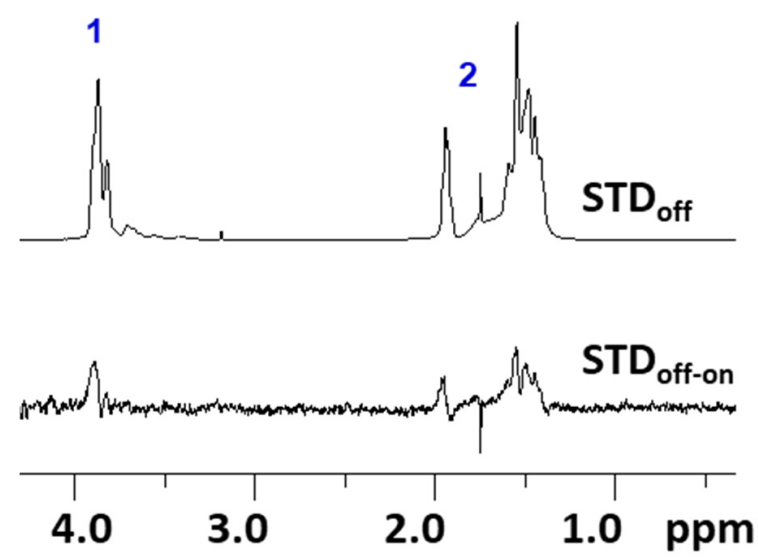

Figure S17. IF-STD spectra $(750 \mathrm{MHz}, 298 \mathrm{~K}$, on-saturation at $0.00 \mathrm{ppm}$, saturation time $3 \mathrm{~s}$ ) of poly(vinyl alcohol) (PVA $306 \mathrm{kDa}, 10 \mathrm{mg} / \mathrm{mL}$ in $\mathrm{D}_{2} \mathrm{O}$ ). Vertical scale of $\mathrm{STD}_{\text {off-on }}$ spectrum is shown $100 \times$. 


\section{Polyacrylamide}
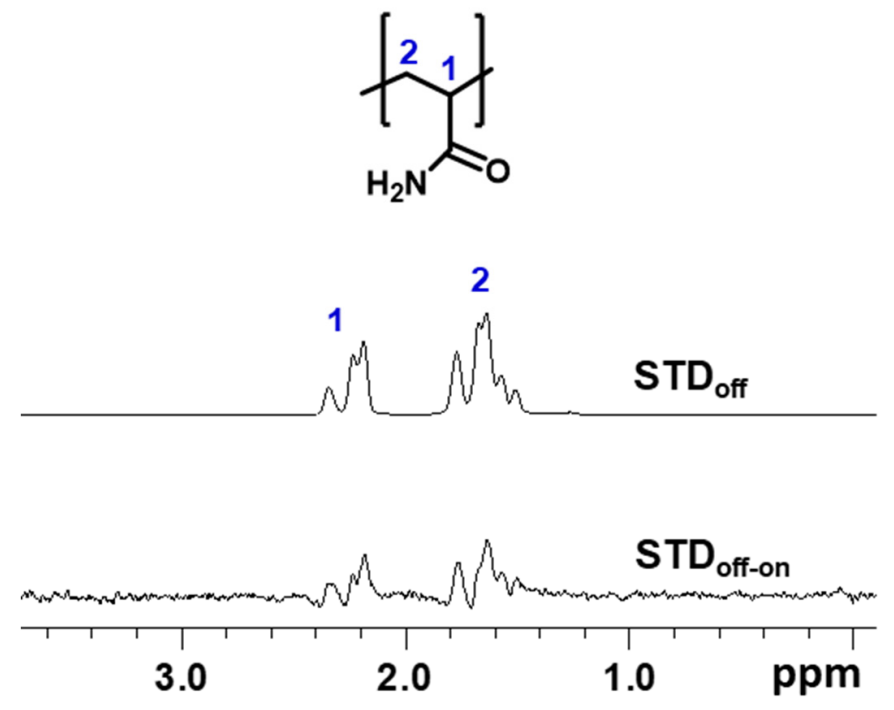

Figure S18. IF-STD spectra ( $750 \mathrm{MHz}, 298 \mathrm{~K}$, on-saturation at $-0.10 \mathrm{ppm}$, saturation time $3 \mathrm{~s})$ of

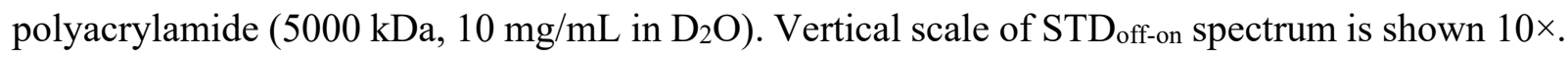




\section{Poly-L-lysine}
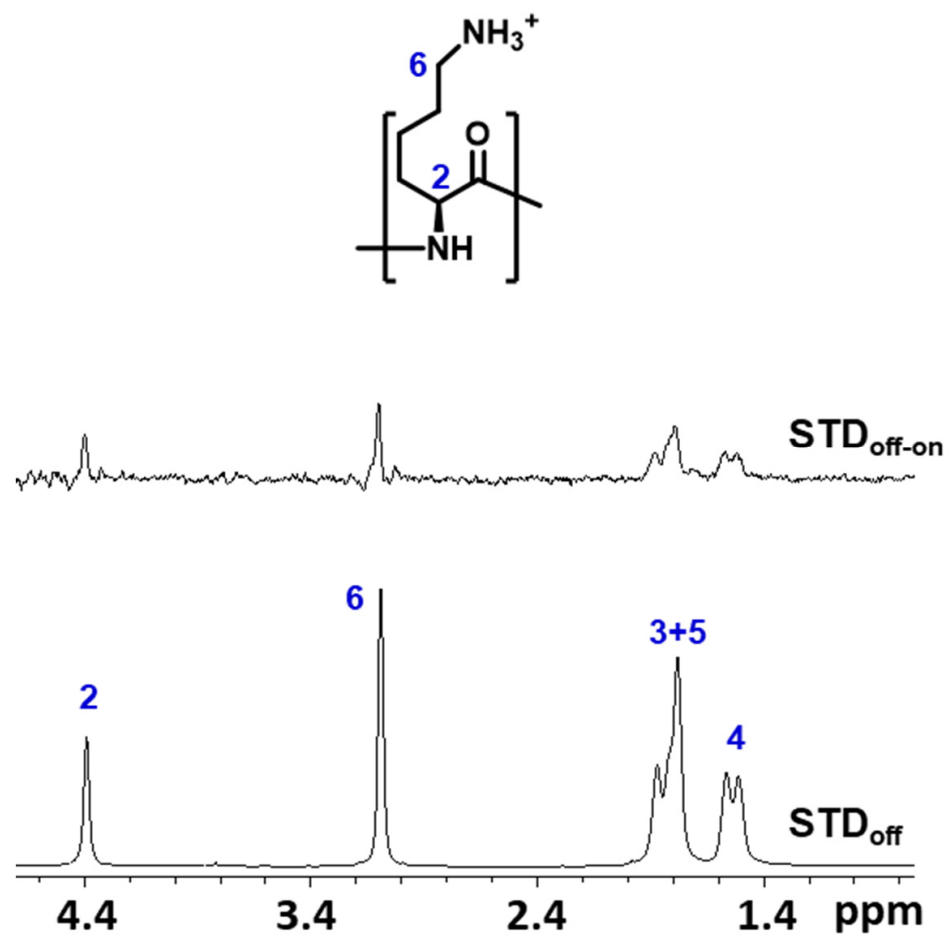

Figure S19. IF-STD spectra (750 MHz, $298 \mathrm{~K}$, on-saturation at $-0.22 \mathrm{ppm}$, saturation time $3 \mathrm{~s}$ ) of poly-L-lysine (PLL $45 \mathrm{kDa}, 10 \mathrm{mg} / \mathrm{mL}$ in $\mathrm{D}_{2} \mathrm{O}$ ). Vertical scale of $\mathrm{STD}_{\text {off-on }}$ spectrum is shown $100 \times$. 


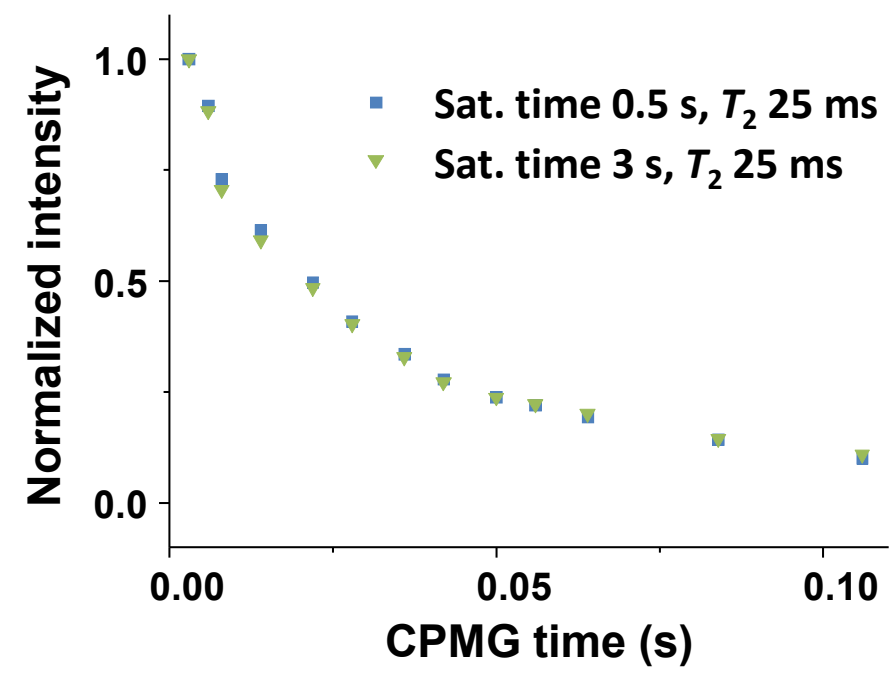

Figure S20. Normalized ${ }^{1} \mathrm{H}$ intensities $\left(\mathrm{I} / \mathrm{I}_{0}\right)$ for the $\mathrm{H} 2$ of CS $(80 \mathrm{kDa}$, DA $14,10 \mathrm{mg} / \mathrm{mL}$ in $\mathrm{pD}$ 4.5 acetate buffer) as a function of the CPMG time in hybrid IF-STD off-CPMG (750 MHz, $298 \mathrm{~K}$ ). Saturation times of 0.5 and $3 \mathrm{~s}$ led to ${ }^{1} \mathrm{H} T_{2}$ of $25 \mathrm{~ms}$.

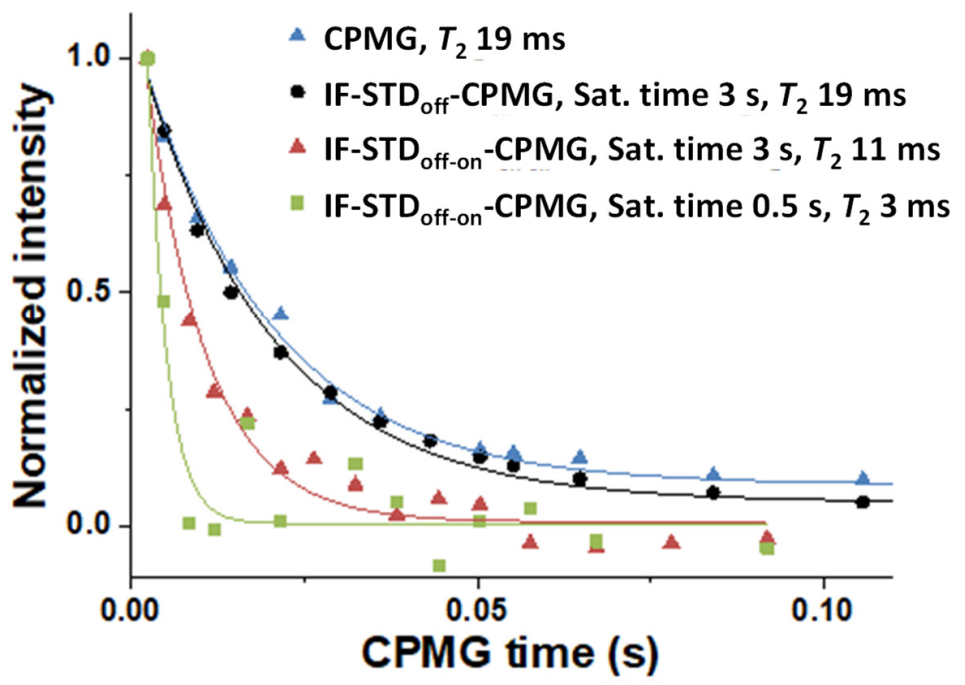

Figure S21. Normalized ${ }^{1} \mathrm{H}$ intensities (I/I0) for the H3-H6 of CS (80 kDa, DA $14,10 \mathrm{~g} / \mathrm{L}$ in pD 4.5 acetate buffer) as a function of the CPMG time in conventional CPMG and hybrid IF-STDCPMG (750 MHz, $298 \mathrm{~K})$. 


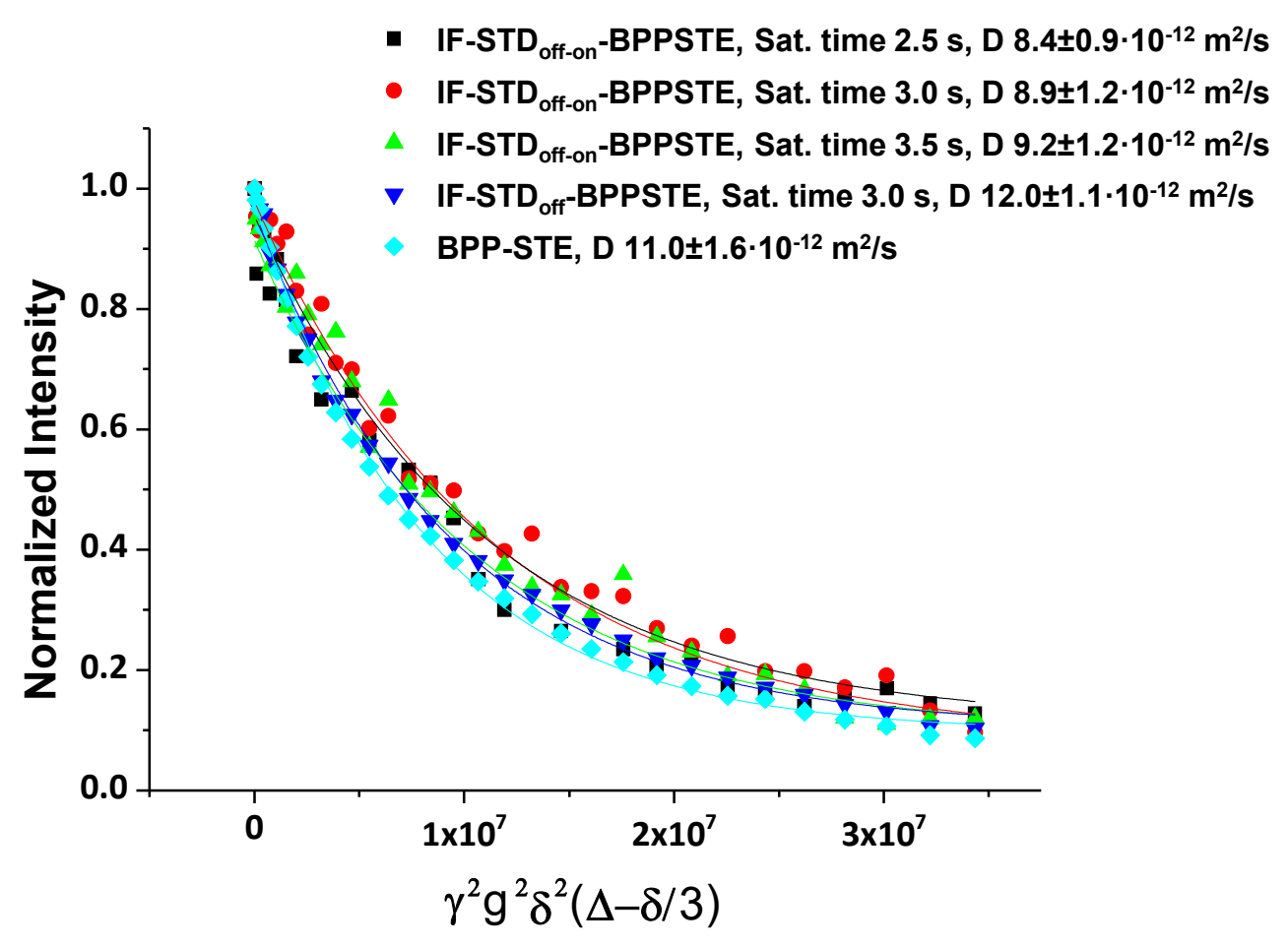

Figure S22. Stejskal-Tanner plots for the H2 of CS $(80 \mathrm{kDa}$, DA $14,10 \mathrm{~g} / \mathrm{L}$ in pD 4.5 acetate buffer) obtained via conventional BPPSTE and hybrid IF-STD-BPPSTE (750 MHz, $298 \mathrm{~K})$. 


\section{References}

1. Fernandez-Megia, E.; Novoa-Carballal, R.; Quiñoá, E.; Riguera, R. Optimal routine conditions for the determination of the degree of acetylation of chitosan by 1H-NMR. Carbohydr. Polym. 2005, 61, 155-161.

2. (a) Tømmeraas, K.; Vårum, K. M.; Christensen, B. E.; Smidsrød, O. Preparation and characterisation of oligosaccharides produced by nitrous acid depolymerisation of chitosans. Carbohydr. Res. 2001, 333, 137-144. (b) Mao, S.; Shuai, X.; Unger, F.; Simon, M.; Bi, D.; Kissel, T. The depolymerization of chitosan: effects on physicochemical and biological properties. Int. J. Pharm. 2004, 281, 45-54.

3. (a) Carr, H. Y.; Purcell, E. M. Effects of Diffusion on Free Precession in Nuclear Magnetic Resonance Experiments. Phys. Rev. 1954, 94, 630-638. (b) Meiboom, S.; Gill, D. Modified SpinEcho Method for Measuring Nuclear Relaxation Times. Rev. Sci. Instrum. 1958, 29, 688-691.

4. (a) Wu, D.; Chen, A.; Johnson Jr., C. S. An Improved Diffusion-Ordered Spectroscopy Experiment Incorporating Bipolar-Gradient Pulses. J. Magn. Reson., Ser. A 1995, 115, 260-264. (b) Johnson Jr., C. S. Diffusion ordered nuclear magnetic resonance spectroscopy: principles and applications. Prog. Nucl. Magn. Reson. Spectrosc. 1999, 34, 203-256. (c) Antalek, B. Using pulsed gradient spin echo NMR for chemical mixture analysis: How to obtain optimum results. Concepts Magn. Reson. 2002, 14, 225-258. 